\title{
The trends and projections in the incidence and mortality of liver cancer in urban Shanghai: a population-based study from 1973 to 2020
}

This article was published in the following Dove Press journal: Clinical Epidemiology

\author{
Lei Bai, ${ }^{1, *}$ Zhenqiu Liu, ${ }^{2,3, *}$ \\ Qiwen Fang, ${ }^{2,3}$ Qiong Yan, ${ }^{4}$ \\ Oumin Shi, ${ }^{5}$ Pingping Bao, ${ }^{6}$ \\ Lina Mu, ${ }^{7}$ Xingdong Chen, ${ }^{8,9}$ \\ Tiejun Zhang ${ }^{2,3}$
}

'Institut Pasteur of Shanghai, Chinese Academy of Sciences, University of Chinese Academy of Sciences, Shanghai, China; ${ }^{2}$ Department of Epidemiology, School of Public Health, Fudan University, Shanghai, China; ${ }^{3}$ Key Laboratory of Public Health Safety, Fudan University, Ministry of Education, Shanghai, China; ${ }^{4}$ Department of Child and Maternal Health, School of Public Health, Fudan University, Shanghai, China; ${ }^{5}$ Department of Neurology, Shenzhen Second People's Hospital, The First Affiliated Hospital of Shenzhen University, Shenzhen, China; ${ }^{6}$ Department of Chronic Non-Communicable Disease Surveillance, Shanghai Municipal Center for Disease Control and Prevention, Shanghai, China; ${ }^{7}$ Department of Epidemiology and Environmental Health, School of Public Health and Health Professions, State University of New York (SUNY) at Buffalo, Buffalo, NY, USA; ${ }^{8}$ State Key Laboratory of Genetic Engineering and Collaborative Innovation Center for Genetics and Development, School of Life Sciences, Fudan University, Shanghai, China; ${ }^{9}$ Fudan University Taizhou Institute of Health Sciences, Taizhou, China

*These authors contributed equally to this work

Correspondence: Xingdong Chen School of Life Sciences, Fudan University, Shanghai 200032, China

Tel/fax +862l 51630602

Email xingdongchen@fudan.edu.cn

Tiejun Zhang

School of Public Health, Fudan University, Shanghai 200032, China

Tel/fax+8621 54237410

Email: tjzhang@shmu.edu.cn
Background: In 2012, liver cancer ranked as the fifth and eighth most common cancer in men and women, respectively, in urban Shanghai. This study aims to present the trend and projection of age-specific incidence and mortality of liver cancer in Shanghai.

Methods: We extracted data of liver cancer incident cases and deaths between 1973 and 2012 . An age-period-cohort model was used to analyze the data.

Results: A total of 47,344 men and 18,692 women were diagnosed with liver cancer from 1973 to 2012 . The overall age-standardized incidence was 26.89 and 8.89 per 100,000 for men and women, respectively. Correspondingly, a total of 44,355 and 18,084 men and women died from liver cancer during this period. The overall age-standardized death rate was 25.34 per 100,000 in men and 9.39 per 100,000 in women. Between 1973 and 2012, liver cancer incidence and mortality in all age groups, except people aged 0-19 years, experienced a significant decline. Similar temporal patterns were detected in liver cancer mortality in both sexes when compared with incidence. Liver cancer incidence and mortality are expected to further decline among all age groups in 2013-2020 in both sexes, though the numbers of incident cases will remain stable.

Conclusion: Incidence and mortality of liver cancer in urban Shanghai have decreased by about $40 \%$ and $50 \%$, respectively, over the past four decades. This decline is expected to continue in the near future. However, the population is aging, which is reflected in the increasing crude rates and decreasing age-adjusted rates.

Keywords: liver cancer, incidence, mortality, Shanghai

\section{Introduction}

China is the country most afflicted by liver cancer in the world. ${ }^{1}$ The estimates of new liver cancer cases and deaths were 355,595 and 322,416, respectively, in China in 2011, which were much higher than those of Western countries. ${ }^{2,3}$ The incidence of liver cancer varies across 31 provinces in mainland China.

In previous decades, Shanghai had a higher liver cancer incidence compared with other provinces, ${ }^{4}$ which may partially be due to the earlier establishment of a cancer registration report system in Shanghai. A previous study reported that the agestandardized incidence rates (ASIRs) of liver cancer in urban Shanghai were 33.9 per 100,000 among men and 11.4 per 100,000 among women between 1976 and 1980 . The incidence decreased to 25.8 and 8.5 per 100,000 in men and women, respectively, by 2001-2005. ${ }^{5}$ It has been well documented that this significant decrease was largely attributed to the wide availability of hepatitis B virus (HBV) vaccines in the last 20-30 years. ${ }^{6}$ The age-patterns in liver cancer incidence as well as the long-term alteration 
of liver cancer mortality, however, have not been well investigated in the Shanghai population.

Additionally, one of the most important sociodemographic changes in Shanghai is the dramatic increase in the number of older adults (age $\geq 65$ years). Specifically, the elderly population in urban Shanghai has increased threefold in the last four decades, with the number increasing from 0.34 million in 1973 to 1.15 million in $2013 .^{7}$ The proportion of older people in urban Shanghai was as high as $18.6 \%$ in 2013 . Since cancer occurs more commonly in older populations, ${ }^{8,9}$ the aging of Shanghai's population is expected to lead to a marked increase in the number of cancer diagnoses as well.

In order to better understand the incidence and mortality trends of liver cancer and provide potential insights for the prevention and control of liver cancer in urban Shanghai, we conducted a population-based study to further investigate the longitudinal changes in morbidity and mortality of liver cancer. These results will be helpful to precisely assess the future burden of liver cancer and subsequently better manage the limited health resources.

\section{Materials and methods Incident cases}

Cancer incidence data during 1973-2012 were obtained from the Shanghai Cancer Registry, which was officially established in 1963 and is one of the largest population-based cancer registries in China. ${ }^{10}$ The Shanghai Cancer Registry is one of the earliest associated members of the World Health Organization International Agency for Research on Cancer. Incident cases of liver cancer were identified by the International Classification of Diseases for Oncology (third edition) using topography code C22.

\section{Death cases}

Data on cause of death between 1973 and 2012 were reported by the Shanghai Centers for Disease Control and Prevention. Deaths caused by liver cancer were identified based on the International Classification of Diseases version nine codes for deaths registered from 1973 to 1994 and on the 10th version of International Classification of Diseases thereafter.

\section{Population}

The total population at the end of each year during the study period was provided by the Shanghai Municipal Bureau of Public Security. The mid-year population by sex was estimated as the average of the calendar years before and after each midpoint, and was used as the annual average population and a surrogate for the person-year at risk. Furthermore, the population was divided into 18 age groups of 5-year intervals stratified by sex. The population data used for the projection of the cancer burden was estimated using the Cohort Component Method. ${ }^{11}$ Age-specific fertility and mortality rates were obtained from the Sixth National Population Census conducted in 2010. We assume that the death rates are constant from 2010 to 2020 , while the fertility rates will experience a slight increase because of the universal two-child policy in China. The fertility rate in 2010 was multiplied by 1.1 to estimate the average fertility rate in 2013-2020.

\section{Statistical analysis}

The population was divided into five age groups (0-19, 20-34, 35-49, 50-64, and 65+ years) to study the age-pattern of liver cancer, and the study period was divided into four intervals (1973-1982, 1983-1992, 1993-2002, and 20032012) to describe the period-pattern of liver cancer. Ageadjusted and truncated (35-64 years) rates were calculated. The standard world population (World Health Organization, 2000) was used to directly standardize the incidence rates in each age group. The estimated annual percentage change (EAPC) was applied to quantify the cancer incidence trend. ${ }^{12}$ A regression line was fitted to the natural logarithm of the rates; that is, $y=\alpha+\beta x+\varepsilon$, where $y=\ln$ (rate) and $x=$ calendar year, and the EAPC was calculated as $100 \times(\exp (\beta)-1) .^{5}$

Age-period-cohort analyses of morbidity and mortality rates were conducted for 10 birth year intervals from 1893-1902 to 2003-2012, 5-year age groups from 0-4 to 75-79, and 10-year calendar periods from 1973-1982 to 2003-2012 to provide matched birth cohorts, age groups, and periods. The relationship between age group, birth cohort, and period was estimated using the method of Clayton and Schifflers. ${ }^{13,14}$ A Bayesian age-period-cohort analysis with integrated nested Laplace approximation was conducted to project age-specific cancer incidence and mortality in future 8 years (2013-2020). ${ }^{15}$ Due to the expectation that effects adjacent in time might be similar, the second-order random walk (RW2) model with inverse-gamma prior distribution was used for age, period, and cohort effects. ${ }^{16}$

All statistics were implemented in R software (Version 3.3.3). Age-period-cohort (APC) analyses were implemented with Epi package, ${ }^{17}$ and the Bayesian APC model was conducted with BAPC ${ }^{15}$ and integrated nested Laplace approximation package ${ }^{18}$ in $\mathrm{R}$.

This study was undertaken with the registry data from the Shanghai Cancer Registry, which is freely available, and no private information was collected as part of this study. 
Therefore, no approval from an ethics committee or informed consent from patients is required for this study.

\section{Results}

\section{Liver cancer incidence}

All reported incidence rates are per 100,000 people. A total of 47,344 men and 18,692 women were diagnosed with liver cancer from 1973 to 2012 . The incidence was higher for men than for women. The overall crude incidence in both sexes increased with time, and peaked at 40.28 in men and 16.23 in women in 2003-2012. However, the ASIRs had decreased over time, with the lowest observed incidences being 20.65 in men and 6.63 in women in 2003-2012 (Table 1, Figure 1).

ASIRs of liver cancer decreased in all age groups between 1973 and 2012, except for people aged 0-19 years for whom the overall EAPC was -1.68 (95\% CI: $-4.17,0.88)$ in men and $-0.51(95 \% \mathrm{CI}:-3.39,2.47)$ in women (Table 2). For men aged 20-34, the incidence rates decreased from 2.94 in 1973-1982 to 1.11 in 2003-2012, with an overall EAPC of -3.39 (95\% CI: $-4.16,-2.60$; Table 2). Among men aged 35-49 years, the incidence rate decreased from 29.90 in 1973-1982 to 15.99 in 2003-2012, with an overall EAPC of -1.94 (95\% CI: $-2.40,-1.58)$. Among men aged 50-64 years, the incidence rate decreased from 87.66 in 1973-1982 to 66.79 in $2003-2012$ (EAPC $=-1.82,95 \% \mathrm{CI}:-2.07,-1.58)$, though significant decrease was only detected in 1983-1992 $(\mathrm{EAPC}=-2.11,95 \% \mathrm{CI}:-3.12,-1.10)$. Among men aged above 65 years, the incidence decreased from 151.22 in 1973-1982 to 118.93 in 2003-2012, with an overall EAPC of -0.82 (95\% CI: $-1.12,-0.52)$. The period-specific EAPCs are shown in Table 2. Similar temporal patterns were observed among women. The overall EAPCs in age groups, except for the $0-19$ year group, were -2.37 (95\% CI: $-3.50,-1.23)$,
-2.40 (95\% CI: $-2.96,-1.83),-2.71$ (95\% CI: $-3.06,-2.35)$, and -0.95 (95\% CI: $-1.22,-0.69)$, respectively (Table 2$)$.

\section{Liver cancer mortality}

A total of 44,355 men and 18,084 women died from liver cancer during 1973-2012 (Table 3). The crude mortality rates and age-standardized mortality rates (ASMRs) in both sexes decreased during this period (Table 3; Figure 1). The overall ASMR was 25.34 in men and 9.39 in women (Table 3).

Between 1973 and 2012, ASMR in all age groups, except for the 0-19 group, showed a significantly decreasing trend (Table 4). In men aged 20-34 years, for example, the overall liver cancer mortality fell from 2.54 in 1973-1982 to 0.73 in 2003-2012, with an integrated EAPC of -4.26 (95\% CI: $-5.40,-3.12)$. Among men aged $35-49$ and 50-64, the overall EAPC was -2.60 (95\% CI: $-3.03,-2.16)$ and -2.54 (95\% CI: $-2.78,-2.31)$, respectively. A slightly decreasing trend was detected in men aged $65+(\mathrm{EAPC}=-1.23,95 \% \mathrm{CI}:-1.52$, $-0.94)$. In this age group, the mortality rate was as high as 163.57 in 1973-1982, which then slowly decreased to 145.96 in 1993-2002, followed by a dramatic drop to 110.53 in 2003-2012. Significant lower death rates were observed for women compared to men in all age groups and time periods. All age groups in women showed a significant decreasing trend during the study period, with the exception of individuals aged $0-19(\mathrm{EAPC}=1.13,95 \% \mathrm{CI}:-2.29,4.66$; Table 4).

\section{Age-period-cohort effects}

Figures 2 and 3 display the age-cohort and age-period effects of liver cancer. As shown in Figure 2, both incidence and mortality of liver cancer increased with age in most birth cohorts. Horizontally, the age-cohort lines were steepest in younger people and were nearly level in older people.

Table I Incidence of liver cancer in Shanghai from 1973 to 2012

\begin{tabular}{|c|c|c|c|c|c|c|c|c|c|c|}
\hline \multirow[t]{2}{*}{ Sex } & \multirow[t]{2}{*}{ Period } & \multirow[t]{2}{*}{ Cases } & \multirow[t]{2}{*}{$\operatorname{ASR}\left(/ 10^{5}\right)$} & \multirow[t]{2}{*}{$\operatorname{CIR}\left(/ 10^{5}\right)$} & \multicolumn{5}{|c|}{$\operatorname{ASR}\left(/ 10^{5}\right)$} & \multirow[t]{2}{*}{ TR (35-64 years) } \\
\hline & & & & & $0-19$ & $20-34$ & $35-49$ & $50-64$ & $65+$ & \\
\hline \multicolumn{11}{|c|}{ Male } \\
\hline & $1973-1982$ & $|0,78|$ & 33.59 & 37.39 & 0.62 & 2.94 & 29.90 & 87.66 & 151.22 & 70.62 \\
\hline & 1983-1992 & 12,337 & 28.54 & 35.31 & 0.40 & 2.87 & 20.23 & 72.88 & 150.99 & 55.03 \\
\hline & 1993-2002 & II,757 & 25.07 & 36.40 & 0.22 & 2.02 & 20.58 & 58.66 & 142.03 & 47.49 \\
\hline & $2003-2012$ & 12,469 & 20.65 & 40.28 & 0.33 & I.II & 15.99 & 50.12 & I I8.93 & 39.53 \\
\hline & Total & 47,344 & 26.89 & 36.98 & 0.39 & 2.12 & 19.46 & 66.79 & 143.39 & 52.49 \\
\hline \multicolumn{11}{|c|}{ Female } \\
\hline & $1973-1982$ & 4021 & 11.53 & 14.28 & 0.26 & 0.74 & 6.18 & 25.82 & 76.98 & 19.09 \\
\hline & $1983-1992$ & 4926 & 10.03 & 14.69 & 0.23 & 0.82 & 4.18 & 22.16 & 72.46 & 15.46 \\
\hline & 1993-2002 & 4733 & 8.48 & 15.11 & 0.30 & 0.53 & 3.87 & 16.01 & 68.04 & 11.95 \\
\hline & $2003-2012$ & 5012 & 6.63 & 16.23 & 0.20 & 0.40 & 2.79 & 11.38 & 58.97 & 8.45 \\
\hline & Total & 18,692 & 8.89 & 15.02 & 0.25 & 0.61 & 3.99 & 18.32 & 68.89 & 15.17 \\
\hline
\end{tabular}

Abbreviations: ASR, age-standardized incidence rate; CIR, crude incidence rate; TR, truncated rate. 


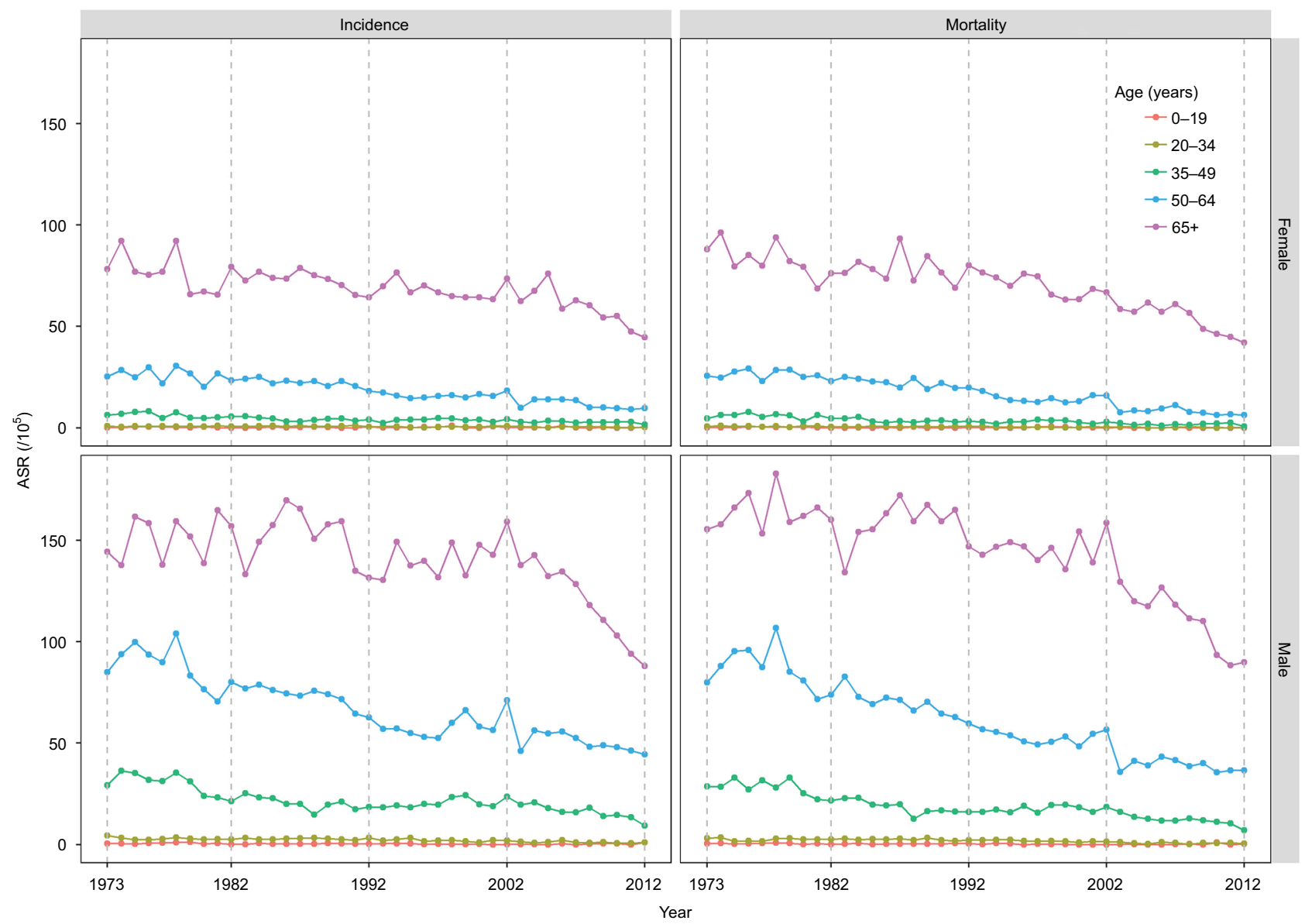

Figure I Age-standardized incidence and mortality per 100,000 cases of liver cancer in urban Shanghai from 1973 to 2012 stratified by sex and age group. Abbreviation: ASR, age-standardized incidence rate.

Table 2 The estimated annual percentage changes of liver cancer incidence in Shanghai from 1973 to 2012

\begin{tabular}{|c|c|c|c|c|c|c|}
\hline \multirow[t]{2}{*}{ Sex } & \multirow[t]{2}{*}{ Period } & \multicolumn{5}{|l|}{$\operatorname{EAPC}(95 \% \mathrm{Cl})$} \\
\hline & & $0-19$ & $20-34$ & $35-49$ & $50-64$ & $65+$ \\
\hline \multicolumn{7}{|c|}{ Male } \\
\hline & $1973-1982$ & $-5.87(-2|.95| 3.52)$, & $-2.84(-7.34,1.87)$ & $-4.60(-7.74,-1.35)$ & $-2.42(-4.90,0.12)$ & $0.77(-1.02,2.60)$ \\
\hline & $1983-1992$ & $9.10(-8.66,30.32)$ & $-0.37(-3.86,3.24)$ & $-3.31(-6.30,-0.23)$ & $-2.11(-3.12,-1.10)$ & $-0.65(-3.03,1.77)$ \\
\hline & 1993-2002 & $-19.65(-35.88,0.70)$ & $-3.84(-10.51,3.33)$ & $1.99(-0.38,4.43)$ & I.8I $(-0.30,3.97)$ & I. $10(-0.4 \mathrm{I}, 2.64))$ \\
\hline & $2003-2012$ & $3.78(-8,83,7.35)$ & $-6.08(-|4.29,2.9|)$ & $-6.48(-9.21,-3.66)$ & $-1.70(-3.47,0.10)$ & $-5.22(-6.38,-4.05)$ \\
\hline & Total & $-1.68(-4.17,0.88)$ & $-3.39(-4.16,-2.60)$ & $-1.94(-2.40,-1.47)$ & $-1.82(-2.07,-1.58)$ & $-0.82(-1.12,-0.52)$ \\
\hline \multicolumn{7}{|c|}{ Female } \\
\hline & $1973-1982$ & $-2.92(-27.06,29.21)$ & $0.40(-5.72,6.93)$ & $-4.09(-8.57,0.60)$ & $-1.26(-4.57,2.17)$ & $-1.89(-4.68,0.98)$ \\
\hline & $1983-1992$ & $-2.46(-22.32,22.47)$ & $-1.30(-8.87,6.90)$ & $-2.74(-7.60,2.38)$ & $-2.44(-3.97,-0.89)$ & $-1.51(-2.72,-0.28)$ \\
\hline & $1993-2002$ & $15.43(-13.28,53.67)$ & $5.18(-6.10,17.83)$ & I.66 (-3.9।, 7.55)) & $0.63(-1.18,2.48)$ & $-0.80(-2.36,0.78)$ \\
\hline & $2003-2012$ & $20.44(-16.02,72.73)$ & $-2.59(-15.70,12.57)$ & $-3.02(-7.67,1.86)$ & $-3.80(-7.53,0.07)$ & $-4.38(-6.47,-2.24)$ \\
\hline & Total & $-0.5 \mathrm{I}(-3.39,2.47)$ & $-2.37(-3.50,-1.23)$ & $-2.40(-2.96,-1.83)$ & $-2.71(-3.06,-2.35)$ & $-0.95(-1.22,-0.69)$ \\
\hline
\end{tabular}

Note: Bold text indicates a significant result.

Abbreviation: EAPC, estimated annual percentage change.

Vertically, lower incidence and mortality rates were detected among younger birth cohorts. As shown in Figure 3, both incidence and mortality continuously increased with age throughout the study period. In the periods 1983-1992, 1993-2002, and 2003-2012, incidence and mortality were lowest at about age 10, after which they increased sharply.
However, these increases slowed among individuals aged above 40 years. This trend was much more obvious in men compared to women. Overall, the age-specific incidence and mortality rates were higher in earlier periods in both sexes. The figures and parameters of the APC models are presented in Figures S1 and S2, and Table S1. 
Table 3 Mortality of liver cancer in Shanghai from 1973 to 2012

\begin{tabular}{|c|c|c|c|c|c|c|c|c|c|c|}
\hline \multirow[t]{2}{*}{ Sex } & \multirow[t]{2}{*}{ Period } & \multirow[t]{2}{*}{ Deaths } & \multirow[t]{2}{*}{$\operatorname{ASR}\left(/ 10^{5}\right)$} & \multirow[t]{2}{*}{$\operatorname{CIR}\left(/ 10^{5}\right)$} & \multicolumn{5}{|c|}{$\operatorname{ASR}\left(/ 10^{5}\right)$} & \multirow[t]{2}{*}{ TR (35-64 years) } \\
\hline & & & & & $0-19$ & $20-34$ & $35-49$ & $50-64$ & $65+$ & \\
\hline \multicolumn{11}{|c|}{ Male } \\
\hline & $1973-1982$ & 10,729 & 33.59 & 37.20 & 0.49 & 2.54 & 27.94 & 86.51 & 163.57 & 68.61 \\
\hline & $1983-1992$ & 12,052 & 27.82 & 34.94 & 0.40 & 2.51 & 18.28 & 69.18 & 157.74 & 51.80 \\
\hline & 1993-2002 & 11,097 & 23.55 & 34.33 & 0.17 & 1.77 & 17.58 & 52.96 & 145.96 & 42.19 \\
\hline & $2003-2012$ & 10,477 & 16.98 & 33.85 & 0.19 & 0.73 & 11.97 & 38.84 & 110.53 & 30.28 \\
\hline & Total & 44,355 & 25.34 & 34.88 & 0.25 & 2.12 & 18.32 & 57.88 & 149.87 & 48.97 \\
\hline \multicolumn{11}{|c|}{ Female } \\
\hline & $1973-1982$ & 4102 & 11.79 & 14.56 & 0.21 & 0.69 & 5.72 & 26.14 & 82.93 & 18.91 \\
\hline & $1983-1992$ & 5084 & 10.20 & 15.16 & 0.14 & 0.65 & 3.48 & 21.93 & 78.60 & 14.93 \\
\hline & 1993-2002 & 4592 & 8.02 & 14.65 & 0.21 & 0.37 & 3.02 & 14.49 & 69.86 & 10.43 \\
\hline & $2003-2012$ & 4306 & 5.34 & 13.95 & 0.12 & 0.26 & 1.71 & 7.97 & 53.39 & 5.84 \\
\hline & Total & 18,084 & 9.39 & 14.62 & 0.18 & 0.52 & 3.42 & 16.34 & 70.22 & 13.87 \\
\hline
\end{tabular}

Abbreviations: ASR, age-standardized incidence rate; CIR, crude incidence rate; TR, truncated rate.

Table 4 The estimated annual percentage changes of liver cancer mortality in Shanghai from I973 to 2012

\begin{tabular}{|c|c|c|c|c|c|c|}
\hline \multirow[t]{2}{*}{ Sex } & \multirow[t]{2}{*}{ Period } & \multicolumn{5}{|l|}{$\operatorname{EAPC}(95 \% \mathrm{Cl})$} \\
\hline & & $0-19$ & $20-34$ & $35-49$ & $50-64$ & $65+$ \\
\hline \multicolumn{7}{|c|}{ Male } \\
\hline & $1973-1982$ & $-8,62(-22.63,7.94)$ & $0.38(-6.81,8.13)$ & $-3.04(-6.00,0.02)$ & $-1.86(-4.68,1.05)$ & $0.25(-1.16,1.69)$ \\
\hline & $1983-1992$ & $7.29(-10.32,28.37)$ & $-2.77(-6.38,0.97)$ & $-4.25(-7.37,-1.01)$ & $-2.69(-3.75,-1.61)$ & $0.86(-0.94,2.69)$ \\
\hline & $1993-2002$ & $-21.26(-49.46,22.68)$ & $-6.24(-10.34,-1.95)$ & $1.12(-1.20,3.49)$ & $-0.30(-1.81,1.23)$ & $0.33(-0.92,1.60)$ \\
\hline & $2003-2012$ & $35.69(1.03,82.26)$ & $-3.52(-17.5|| 2.83)$, & $-5.79(-8.8 \mathrm{I},-2.67)$ & $-0.83(-2.51,0.88)$ & $-4.18(-5.62,-2.71)$ \\
\hline & Total & $-2.66(-5.35,0.12)$ & $-4.26(-5.40,-3.12)$ & $-2.60(-3.03,-2.16)$ & $-2.54(-2.78,-2.3 I)$ & $-1.23(-1.52,-0.94)$ \\
\hline \multicolumn{7}{|c|}{ Female } \\
\hline & $1973-1982$ & $|3.3|(-16.94,54.55)$ & $-3.06(-1 \mathrm{I} .8 \mathrm{I}, 6.56)$ & $-2.32(-8.82,4.64)$ & $-0.57(-2.83,1.75)$ & $-2.18(-4.11,-0.20)$ \\
\hline & $1983-1992$ & $-5.86(-38.27,43.57)$ & $-0.21(-6.01,5.94)$ & $-3.55(-8.65,1.83)$ & $-2.44(-4.27,-0.57)$ & $-0.43(-2.66,1.85)$ \\
\hline & $1993-2002$ & $-1.17(-34.29,48.63)$ & $-8.67(-22.20,7.20)$ & $-0.26(-6.5 I, 6.4 I)$ & $-0.72(-3.91,2.59)$ & $-1.79(-3.11,-0.45)$ \\
\hline & $2003-2012$ & $1.35(-35.60,59.50)$ & $-7.31(-22.86,11.39)$ & $-2.79(-12.36,7.83)$ & $-3.56(-7.29,0.33)$ & $-3.98(-5.70,-2.22)$ \\
\hline & Total & I.I3 $(-2.29,4.66)$ & $-3.4 I(-4.76,-2.03)$ & $-3.69(-4.47,-2.89)$ & $-3.8 I(-4.26,-3.35)$ & $-1.48(-1.75,-1.2 I)$ \\
\hline
\end{tabular}

Note: The cells in bold format show significant EAPC.

Abbreviation: EAPC, estimated annual percentage change.

\section{Projections of liver cancer incidence and mortality}

In 2010 , the proportion of elderly people (aged 65+) was $16.9 \%$ in urban Shanghai, and this proportion increased to $18.8 \%$ in 2015 and is expected to be $25.4 \%$ in 2020 . The number of elderly people increased from $1,047,125$ in 2010 to 1,217,748 in 2015 and is expected to be 1,603,661 in 2020 . The sex ratio $(\mathrm{M} / \mathrm{F})$ in this age group was 0.84 in 2010, 0.89 in 2015, and is expected to be 0.89 in 2020. The whole population in urban Shanghai, however, is predicted to remain relatively stable $(6,194,982$ in 2010 and 5,941,427 in 2020) according to our results (data not shown). The number of new cases is expected to decrease slightly from 1101 in 2012 to 913 (95\% CI: 824.23, 982.31) in 2020 in men. In contrast, it is anticipated to increase from 456 in 2012 to 471 (95\% CI: 398.43, 587.23) in women. Liver cancer incidence and mortality are expected to further decline in all age groups between 2013 and 2020 in both sexes (Figure 4; Tables S2 and S3). Specifically, for men aged $65+$, the incidence rate is predicted to decrease from 102.92 (95\% CI: $77.44,134.28)$ in 2013 to 69.97 (95\% CI: $41.78,105.39)$ in 2020 , with an EAPC of -5.35 (95\% CI: $-5.77,-4.92)$. The greatest decline is expected to occur in the 50-64 group, with an annual decrease of $-7.13 \%$ (95\% CI: $-7.25 \%,-7.01 \%$ ) from 52.89 (95\% CI: $39.90,68.68)$ in 2013 to 31.68 (95\% CI: $18.59,48.65)$ in 2020 . Lower EAPCs are expected in each age group for women compared to men, with the greatest decline in the $65+$ group. In this group, the incidence rate is predicted to decrease by $-3.76 \%$ (95\% CI: $-3.96 \%,-3.57 \%$ ) per year during 2013-2020. Similar temporal patterns were projected in liver cancer mortality in both sexes. 
A

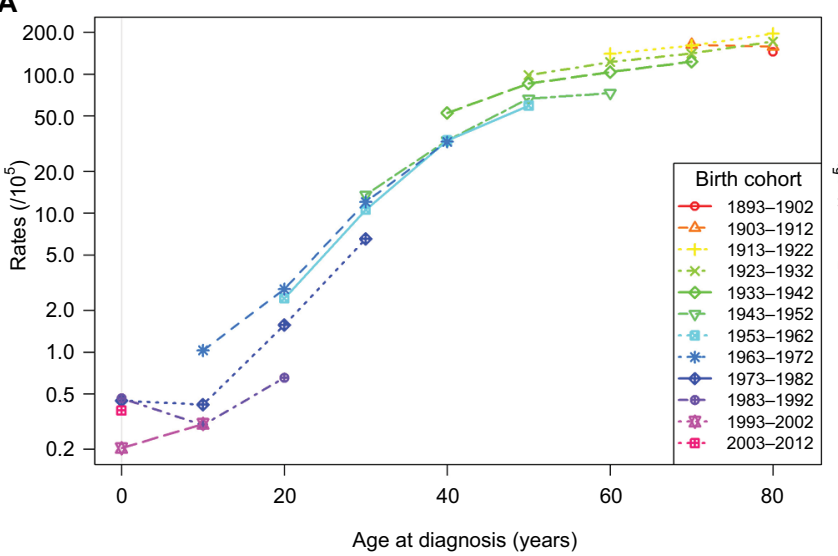

C

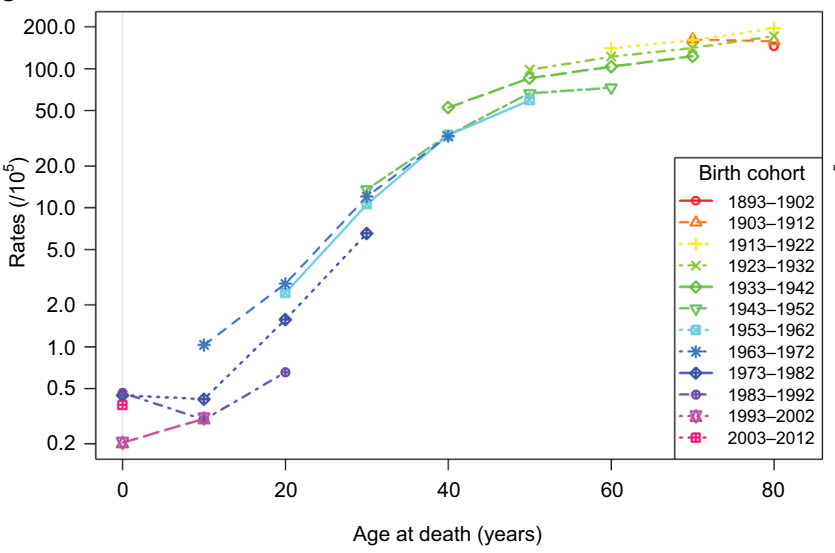

B

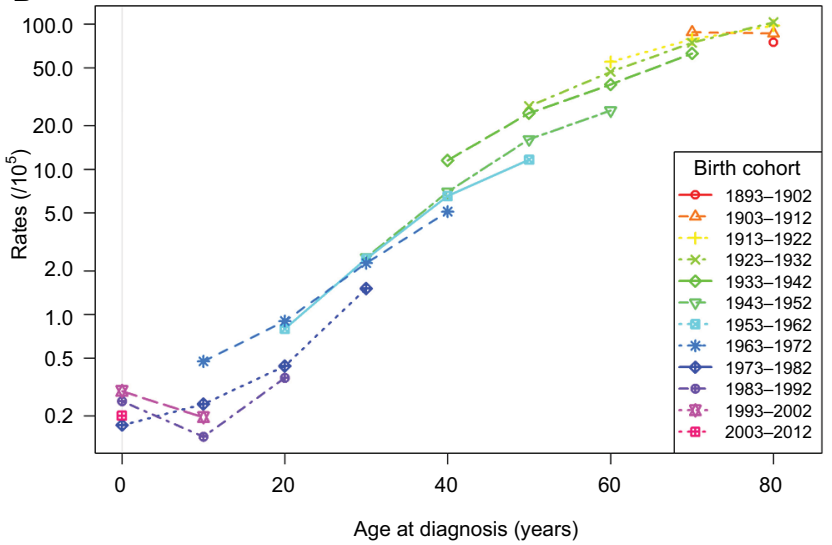

D

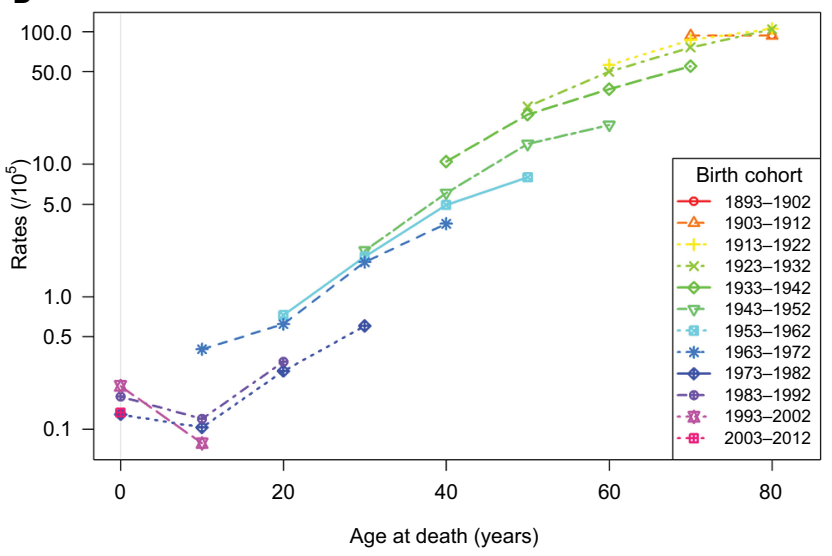

Figure 2 Age-standardized incidence and mortality per 100,000 cases of liver cancer in urban Shanghai from 1973 to 2012 by birth cohort and age. Notes: (A) Incidence in males; (B) incidence in females; (C) mortality in males; (D) mortality in females.

\section{Discussion}

Liver cancer is one of the primary lethal neoplasms in China, with an incidence rate that is $5-10$ times higher than that in most European and American populations. ${ }^{19,20}$ A considerable body of evidence has demonstrated that liver cancer incidence varies across China, ${ }^{4}$ with Shanghai being at the lower end compared to other regions of China. For example, the age-adjusted incidence of liver cancer in Qidong, Jiangsu province, an endemic area for liver cancer, was nearly five times higher than that in Shanghai. ${ }^{4}$ In Beijing, the incidence rates were 29.29 and 10.04 per 100,000 for men and women, respectively, in 2004, which were slightly higher than those in Shanghai. ${ }^{4}$

In the present study, we depicted and analyzed the secular trends of incidence and mortality rates of liver cancer in urban Shanghai from 1973 to 2012. Consistent with previous studies, ${ }^{5,24,25}$ our study suggests that the incidence and mortality rates of liver cancer in urban Shanghai have been decreasing over the past four decades, and that these decreases are more pronounced than the national decrease for both men and women. ${ }^{23}$ Ongoing reductions in both the incidence and mortality of liver cancer can be attributed to continuing progress in specific areas of public health and oncology care. Nonsignificant decreases in both incidence and mortality rates over that period, however, were detected among children and adolescents (aged 0-19 years). We further observed that the liver cancer incidence and mortality, which were lowest at about age 10 , did not increase with age in this period. These results can be explained to a large extent by the inclusion of hepatoblastoma, which is the most common liver malignancy in children aged under 5, in the Shanghai Cancer Registry. ${ }^{26}$ It is further of note that the slowest decrease in the study period was observed for people aged 65+, which is not only illustrative of the fact that age is still the most critical risk factor for liver cancer development, but also suggests an accumulation of cases in the aging population in Shanghai.

Different from previous studies, we are the first to predict the disease burden of liver cancer based on demographic changes in Shanghai. Since age is the most important factor in cancer development, ${ }^{27,28}$ aging of Shanghai's population is expected to lead to a marked increase in the number of 

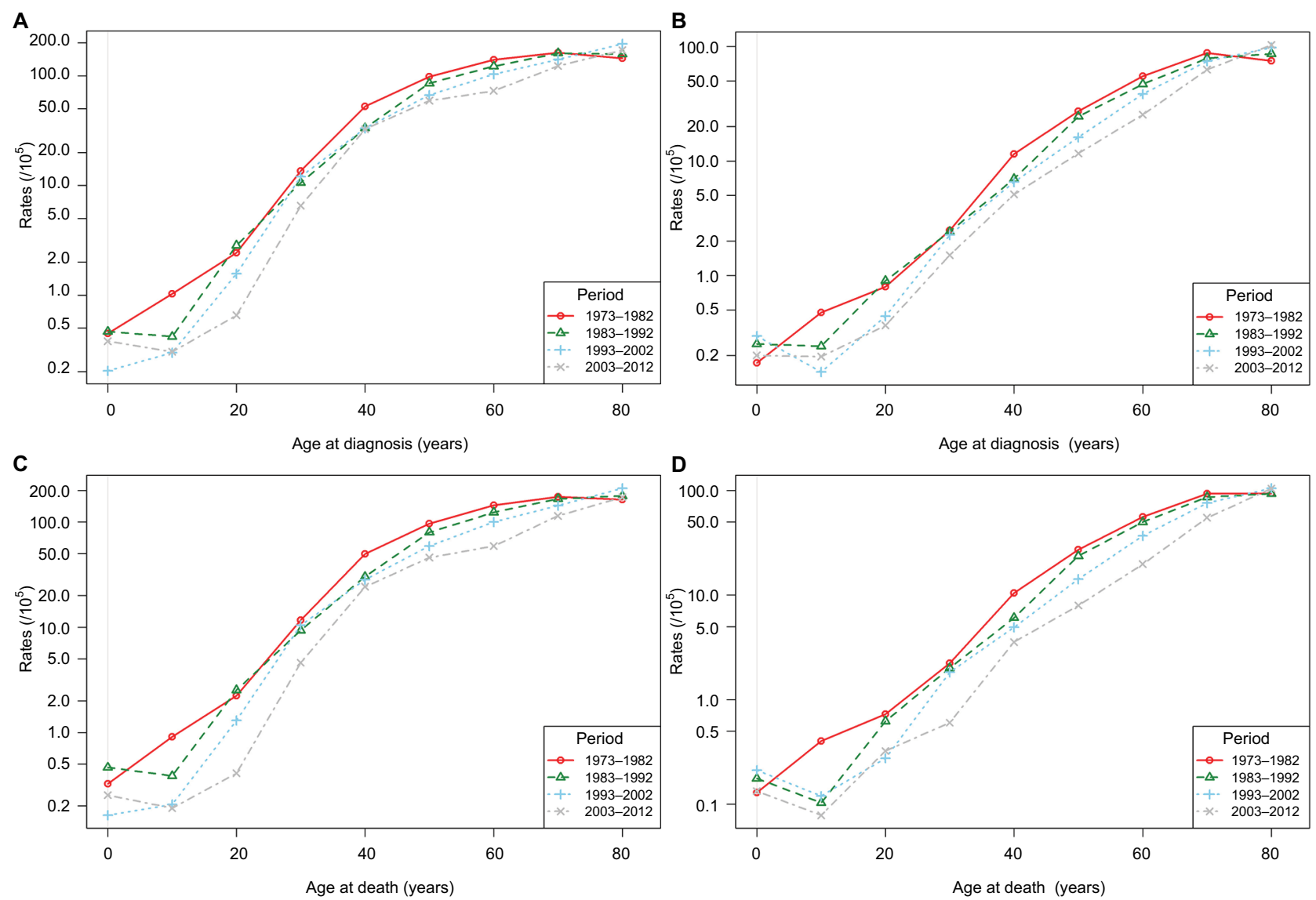

Figure 3 Age-standardized incidence and mortality per 100,000 cases of liver cancer in urban Shanghai from 1973 to 2012 by time period and age. Notes: (A) Incidence in males; (B) incidence in females; (C) mortality in males; (D) mortality in females.

new cancer diagnoses. In this study, we found that the crude incidence of liver cancer had increased over the past four decades, although the age-adjusted incidence had decreased. Meanwhile, the numbers of liver cancer cases are expected to remain relatively stable over the 2013-2020 period. These results further suggested that liver cancer will remain a major health concern in Shanghai in the future.

It is important to realize, however, that the predictions of liver cancer incidence and mortality rates in this study were done without consideration of other potential factors such as obesity and diabetes. Previous studies have demonstrated that the association between obesity/diabetes and liver cancer is particularly strong. Obesity has been associated with liver diseases such as non-alcoholic fatty liver disease and the more severe non-alcoholic steatohepatitis. ${ }^{29,30}$ The prevalence of obesity and diabetes in China has increased substantially over recent decades, ${ }^{31,32}$ which might influence the trend of liver cancer incidence in the near future.

During the previous 40 years, Shanghai has made a tremendous effort to battle with liver cancer. The risk factors for liver cancer have been extensively investigated.
Environmental risk factors of liver cancer, including exposure to aflatoxin B1, alcohol consumption, cigarette smoking, and unhealthy diet, may have partially contributed to the trends in liver cancer incidence observed in Shanghai. ${ }^{33-35}$ Moreover, nearly $80 \%$ of cases of primary liver cancer can be attributed to chronic viral infections with either HBV $(50 \%-55 \%)$ or hepatitis $\mathrm{C}$ virus (HCV; $25 \%-30 \%) .{ }^{36,37}$ According to our unpublished data, HBV incidence was 26.52 per 100,000 in 2004 in Shanghai and remained stable until 2014, while HCV incidence increased rapidly from 1.01 per 100,000 to 7.29 per 100,000 during this period. The constant trend of new HBV infections, especially among young and middle-aged people, was mainly ascribed to the wide coverage of $\mathrm{HBV}$ vaccination. In fact, $95 \%$ of the newborns in urban Shanghai have been inoculated with the HBV vaccine since the year $1992 .{ }^{5}$ The large-scale HBV vaccination of newborns in Shanghai has been shown to be effective and is expected to lead to a further reduction of HBV infections in the future. Consequently, we would expect to see a decrease in the incidence of liver cancer in these children as they become adults. However, the 
A
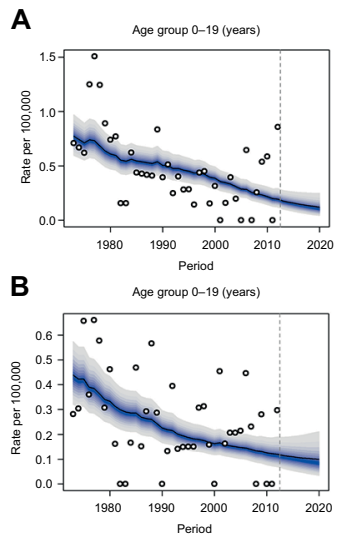

C
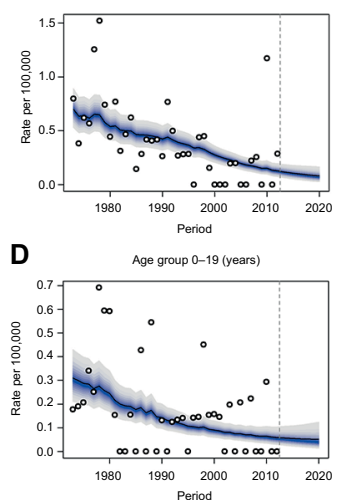

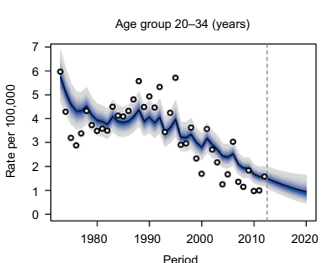

Age group 20-34 (years)

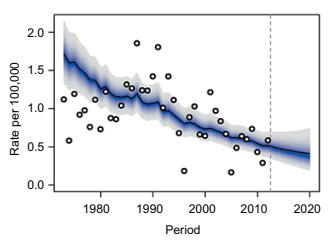

Age group 20-34 (years)

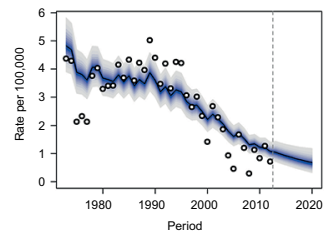

Age group 20-34 (years)

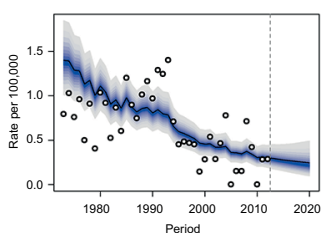

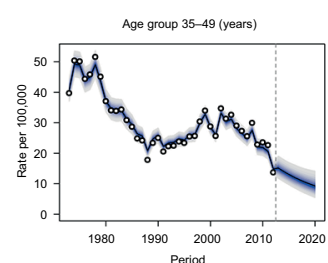

Age group 35-49 (years)

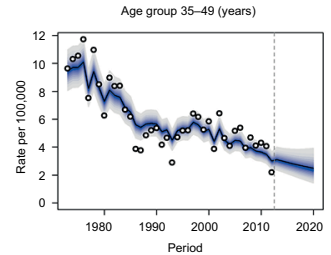

Age group 35-49 (years)

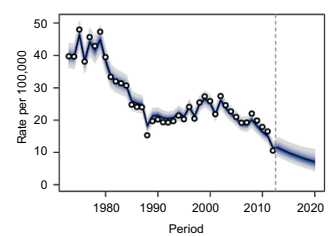

Age group $35-49$ (years)

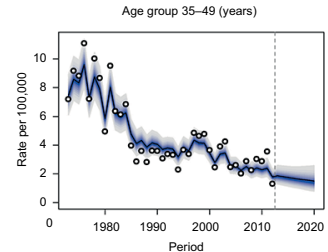

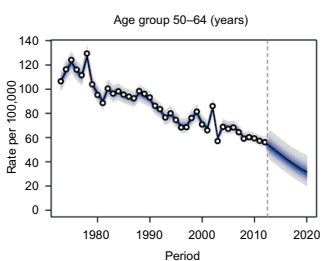

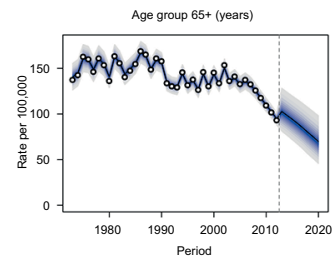

Age group 50-64 (years)

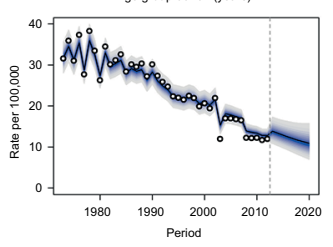

Age group $65+$ (years)

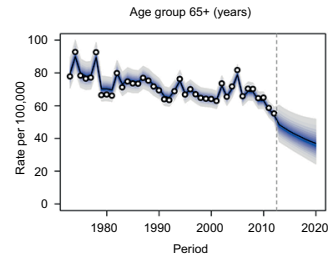

Age group 50-64 (years)
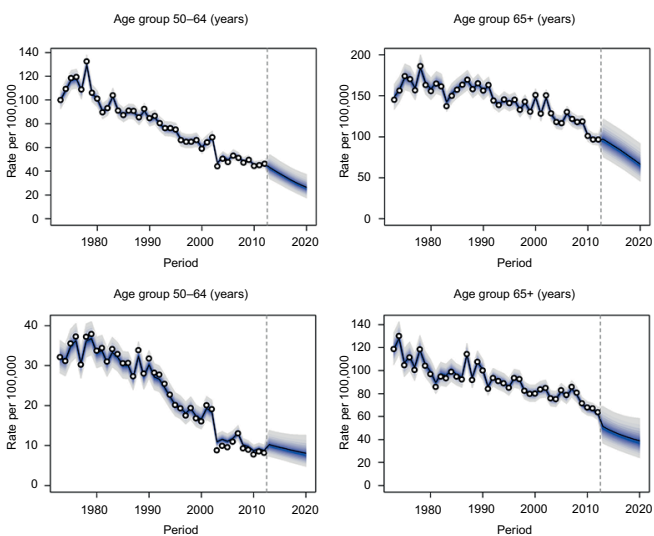

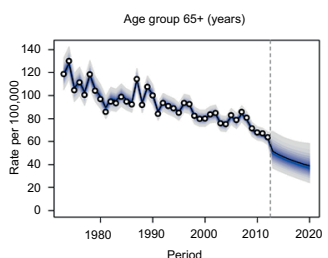

Figure 4 Age-specific liver cancer incidence and mortality forecasts in urban Shanghai from 2013 to 2020

Notes: The fan shows the predictive distribution between the $5 \%$ and $95 \%$ quantile, whereby the shaded bands show prediction intervals in increments of $10 \%$. The predictive mean is shown as a solid line. Observed numbers of cases are shown as an open circle. The vertical dashed line indicates where prediction started. (A) Cancer incidence in men; (B) cancer incidence in women; (C) cancer mortality in men; (D) cancer mortality in women.

emergence of $\mathrm{HCV}$ infection is a new challenge for liver cancer prevention.

We further found that EAPCs were generally higher in women than in men, although not consistently. This sex difference might be attributed to many underlying causes. For example, the prevalence of smoking and alcohol consumption in Shanghai might have decreased much more rapidly in women compared to men. Women might be better protected from HBV infection compared to men because the government has paid more attention to the prevention of motherto-child transmission of HBV. Further studies are needed to confirm these conjectures.

Our study observed parallel reductions in liver cancer mortality. Liver cancer is a malignant carcinoma with poor prognoses. The 5-year survival rate of liver cancer was $9.0 \%$ in Shanghai in the early 1990s, which increased to about $13.0 \%$ in the last decade. ${ }^{38,39}$ Declining trends of liver cancer mortality co-occurred with a decreasing incidence, and this was indicative of the improvements in the health care system and medical capacity in Shanghai.
Some limitations of this study should be mentioned. First, we were not able to resolve the inherited problems of APC models, which include the requirement for arbitrary constraints to achieve identifiability of the effects of age, period, and cohort. Second, liver cancer could not be grouped in terms of the histology, which may, to some extent, bias the results, including the proper explanations of the reduction of liver cancer mortality. Third, hepatoblastoma was not separated from liver cancers. Recent data showed that the incidence of hepatoblastoma has increased by $2.18 \%$ annually in children and adolescents, and that $90 \%$ of patients under 5 years of age with liver malignancies were diagnosed with hepatoblastoma. ${ }^{26}$ Thus, the inclusion of hepatoblastoma will overestimate the primary liver cancer incidence in children and adolescents.

\section{Conclusion}

In summary, we analyzed and projected the age-specific incidence and mortality rates of liver cancer in urban Shanghai from 1973 to 2020 . Although ongoing decreases in these rates 
were observed in people aged above 20 years during the study period, the incidence in Shanghai remains high compared to that in Western countries. As a result, the improvement of liver cancer prevention strategies, such as diminishing HBV and $\mathrm{HCV}$ infections and avoidance of dietary exposure to aflatoxins, remains important for the future. Most importantly, to counteract the effect of an aging population and the effect of an subsequent anticipated surge in cancer incidence, significant research investments are needed.

\section{Acknowledgment}

This work was supported by the National Natural Science Foundation of China (grant numbers: 81502870), the International S\&T Cooperation Program of China (grant number: 2015DFE32790), the China Postdoctoral Science Foundation (grant numbers: 2016M601511 and 2017T100272), the Key Basic Research Grants from Science and Technology Commission of Shanghai Municipality (grant number: 16JC1400500), and the National Key Research and Development program of China (grant number: 2017YFC0907002, 2017YFC0907501).

\section{Disclosure}

The authors report no conflicts of interest in this work.

\section{References}

1. Fitzmaurice C, Allen C, Barber RM, et al. Global, regional, and national cancer incidence, mortality, years of life lost, years lived with disability, and disability-adjusted life-years for 32 cancer groups, 1990 to 2015: a systematic analysis for the global burden of disease study. JAMA Oncol. 2017;3(4):524-548.

2. Altekruse SF, Henley SJ, Cucinelli JE, McGlynn KA. Changing hepatocellular carcinoma incidence and liver cancer mortality rates in the United States. Am J Gastroenterol. 2014;109(4):542-553.

3. Zuo TT, Zheng RS, Zhang SW, Zeng HM, Chen WQ. Incidence and mortality of liver cancer in China in 2011. Chin J Cancer. 2015;34(11):508-513.

4. Chen JG, Zhang SW. Liver cancer epidemic in China: past, present and future. Semin Cancer Biol. 2011;21(1):59-69.

5. Gao S, Yang WS, Bray F, et al. Declining rates of hepatocellular carcinoma in urban Shanghai: incidence trends in 1976-2005. Eur J Epidemiol. 2012;27(1):39-46.

6. Zhang HZ, Wu WS, Su F, et al. [Valuation on the immunization efficacy on the 23 years who had received plasma-derived HBV vaccine as newborns]. Zhonghua Liu Xing Bing Xue Za Zhi. 2012;33(2):207-209. Chinese.

7. Bureau of Statistics of China. Shanghai Statistics Yearbook. Beijing: China Statistics Press; 2014.

8. Chaturvedi AK, Anderson WF, Lortet-Tieulent J, et al. Worldwide trends in incidence rates for oral cavity and oropharyngeal cancers. J Clin Oncol. 2013;31(36):4550-4559.

9. Siegel R, Ma J, Zou Z, Jemal A. Cancer statistics, 2014. CA Cancer J Clin. 2014;64(1):9-29.

10. Curado MP, Edwards B, Shin HR, et al. Cancer Incidence in Five Continents, vol. IX. Lyon: IARC Scientific Publications; 2007.

11. Ormiston-Smith N, Smith J, Whitworth A. An international comparative study on the use of the Cohort Component Method for estimating national populations. Popul Trends. 2006(125):37-46.
12. Hankey BF, Ries LA, Kosary CL, et al. Partitioning linear trends in age-adjusted rates. Cancer Causes Control. 2000;11(1):31-35.

13. Clayton D, Schifflers E. Models for temporal variation in cancer rates. I: AGE-period and age-cohort models. Stat Med. 1987;6(4):449-467.

14. Clayton D, Schifflers E. Models for temporal variation in cancer rates. II: age-period-cohort models. Stat Med. 1987;6(4):469-481.

15. Riebler A, Held L. Projecting the future burden of cancer: Bayesian age-period-cohort analysis with integrated nested Laplace approximations. Biom J. 2017;59(3):531-549.

16. Besag J, Green P, Higdon D, Mengersen K. Bayesian computation and stochastic systems (with discussion). Stat Sci. 1995(10):3-66.

17. Carstensen B. Age-period-cohort models for the Lexis diagram. Stat Med. 2007;26(15):3018-3045.

18. Finn L, Havard R. Bayesian spatial modelling with R-INLA. J Stat Softw. 2015;63(19):1-25.

19. Jack RH, Konfortion J, Coupland VH, et al. Primary liver cancer incidence and survival in ethnic groups in England, 2001-2007. Cancer Epidemiol. 2013;37(1):34-38.

20. Teo MC, Soo KC. Cancer trends and incidences in Singapore. Jpn J Clin Oncol. 2013;43(3):219-224.

21. Ali R, Barnes I, Cairns BJ, et al. Incidence of gastrointestinal cancers by ethnic group in England, 2001-2007. Gut. 2013;62(12):1692-1703.

22. Taylor-Robinson SD, Foster GR, Arora S, Hargreaves S, Thomas HC. Increase in primary liver cancer in the UK, 1979-94. Lancet. 1997;350(9085):1142-1143.

23. Chen W, Zheng R, Baade PD, et al. Cancer statistics in China, 2015. CA Cancer J Clin. 2016;66(2):115-132.

24. Gao YT, Tu JT, Jin F, Gao RN. Cancer mortality in Shanghai during the period 1963-77. Br J Cancer. 1981;43(2):183-195.

25. Jin F, Devesa SS, Zheng W, Blot WJ, Fraumeni JF Jr., Gao YT. Cancer incidence trends in urban Shanghai, 1972-1989. Int J Cancer. 1993; 53(5):764-770.

26. Yuan XJ, Wang HM, Jiang H, et al. Multidisciplinary effort in treating children with hepatoblastoma in China. Cancer Lett. 2016;375(1):39-46.

27. Ryerson AB, Eheman CR, Altekruse SF, et al. Annual report to the nation on the status of cancer, 1975-2012, featuring the increasing incidence of liver cancer. Cancer. 2016;122(9):1312-1337.

28. Smith BD, Smith GL, Hurria A, Hortobagyi GN, Buchholz TA. Future of cancer incidence in the United States: burdens upon an aging, changing nation. J Clin Oncol. 2009;27(17):2758-2765.

29. Sun B, Karin M. Obesity, inflammation, and liver cancer. $J$ Hepatol. 2012;56(3):704-713.

30. Printz C. Diabetes associated with increased risk of liver cancer. Cancer 2014; 120(9):1288.

31. Ma RC, Lin X, Jia W. Causes of type 2 diabetes in China. Lancet Diabetes Endocrinol. 2014;2(12):980-991.

32. Yang W, Lu J, Weng J, et al. Prevalence of diabetes among men and women in China. N Engl J Med. 2010;362(12):1090-1101.

33. Chen ZM, Liu BQ, Boreham J, Wu YP, Chen JS, Peto R. Smoking and liver cancer in China: case-control comparison of 36,000 liver cancer deaths vs. 17,000 cirrhosis deaths. Int J Cancer. 2003;107(1):106-112.

34. Chuang SC, La Vecchia C, Boffetta P. Liver cancer: descriptive epidemiology and risk factors other than HBV and HCV infection. Cancer Lett. 2009;286(1):9-14.

35. Di Bisceglie AM, Carithers RL Jr, Gores GJ. Hepatocellular carcinoma. Hepatology. 1998;28(4):1161-1165.

36. Bosch FX, Ribes J, Diaz M, Cleries R. Primary liver cancer: worldwide incidence and trends. Gastroenterology. 2004;127(5 Suppl 1):S5-S16.

37. Perz JF, Armstrong GL, Farrington LA, Hutin YJ, Bell BP. The contributions of hepatitis $\mathrm{B}$ virus and hepatitis $\mathrm{C}$ virus infections to cirrhosis and primary liver cancer worldwide. J Hepatol. 2006;45(4): 529-538.

38. Han X, Huang CX, Zhang HW, et al. [The occurrence and survival condition of primary liver cancer among residents in Yangpu district of Shanghai between year 2002 and 2010]. Zhonghua Yu Fang Yi Xue Za Zhi. 2012;46(2):119-124. Chinese.

39. Xiang YB, Jin F, Gao YT. Cancer survival in Shanghai, China, 19921995. IARC Sci Pub. 2011(162):55-68. 


\section{Supplementary materials}

Table SI Fitting of the age-period-cohort models for the liver cancer incidence and mortality in Shanghai from 1973 to 2012

\begin{tabular}{|c|c|c|c|c|c|c|}
\hline Sex & Terms in model & Deviance & $d f$ & $\Delta$ deviance & $\Delta d f$ & $P$-value \\
\hline \multicolumn{7}{|c|}{ Incidence } \\
\hline \multirow[t]{6}{*}{ Male } & Age & 3091.0 & 618 & & & \\
\hline & Age-drift & 1604.0 & 617 & 1486.98 & I & $<0.001$ \\
\hline & Age-cohort & 1390.7 & 613 & 213.34 & 4 & $<0.001$ \\
\hline & Age-period-cohort & 1295.3 & 609 & 95.37 & 4 & $<0.001$ \\
\hline & Age-period & 1520.3 & 613 & -224.97 & -4 & $<0.001$ \\
\hline & Age-drift & 1604.0 & 617 & -83.74 & -4 & $<0.001$ \\
\hline \multirow[t]{5}{*}{ Female } & Age & 1688.63 & 578 & & & \\
\hline & Age-drift & 1065.17 & 577 & 623.46 & I & $<0.001$ \\
\hline & Age-cohort & 773.55 & 573 & 291.61 & 4 & $<0.001$ \\
\hline & Age-period-cohort & 685.90 & 569 & 87.65 & 4 & $<0.001$ \\
\hline & Age-period & 1013.04 & 573 & -327.13 & -4 & $<0.001$ \\
\hline \multicolumn{7}{|c|}{ Mortality } \\
\hline \multirow[t]{6}{*}{ Male } & Age & 4440.9 & 714 & & & \\
\hline & Age-drift & 1804.0 & 713 & 2636.96 & I & $<0.001$ \\
\hline & Age-cohort & 1463.6 & 709 & 340.33 & 4 & $<0.001$ \\
\hline & Age-period-cohort & 1337.4 & 705 & 126.23 & 4 & $<0.001$ \\
\hline & Age-period & 1667.2 & 709 & -329.76 & -4 & $<0.001$ \\
\hline & Age-drift & 1804.0 & 713 & -136.80 & -4 & $<0.001$ \\
\hline \multirow[t]{6}{*}{ Female } & Age & $25,918.5$ & 714 & & & \\
\hline & Age-drift & $14,062.0$ & 713 & II,856.5 & I & $<0.001$ \\
\hline & Age-cohort & $13,094.3$ & 709 & 967.7 & 4 & $<0.001$ \\
\hline & Age-period-cohort & 5935.3 & 705 & 7159.0 & 4 & $<0.001$ \\
\hline & Age-period & 6492.3 & 709 & -556.8 & -4 & $<0.001$ \\
\hline & Age-drift & $14,062.0$ & 713 & -7569.9 & -4 & $<0.001$ \\
\hline
\end{tabular}

Table S2 The projection of liver cancer incidence in Shanghai from 2013 to 2020 based on the registry data, $1973-2012$

\begin{tabular}{|c|c|c|c|c|c|c|}
\hline \multirow[t]{2}{*}{ Sex } & \multirow[t]{2}{*}{ Period } & \multicolumn{5}{|c|}{ Age-specific incidence per $10^{5}(95 \% \mathrm{Cl})$} \\
\hline & & $0-19$ & $20-34$ & $35-49$ & $50-64$ & $65+$ \\
\hline \multicolumn{7}{|c|}{ Male } \\
\hline & 2013 & $0.18(0.09,0.30)$ & I.46 $(0.98,2.07)$ & $15.17(\mid 1.23,20.01)$ & $52.89(39.90,68.68)$ & $102.92(77.44,134.28)$ \\
\hline & 2014 & $0.17(0.08,0.30)$ & $1.36(0.88,1.99)$ & $14.05(10.15,18.89)$ & $49.46(36.7 I, 65.01)$ & $98.61(72.95,130.16)$ \\
\hline & 2015 & $0.16(0.07,0.29)$ & $1.28(0.78,1.94)$ & $13.04(9.11,17.95)$ & $46.06(33.42,61.50)$ & $94.16(68.11,126.11)$ \\
\hline & 2016 & $0.15(0.06,0.29)$ & $1.20(0.69,1.90)$ & $12.13(8.15,17.18)$ & $42.74(30.12,58.21)$ & $89.58(63.00,122.08)$ \\
\hline & 2017 & $0.14(0.05,0.29)$ & $\mathrm{I} .13(0.6 \mathrm{I}, \mathrm{I} .87)$ & II.32 (7.25, I6.57) & 39.59 (26.9I, 55.23) & $84.84(57.70,118.02)$ \\
\hline & 2018 & $0.13(0.05,0.29)$ & $1.06(0.53,1.85)$ & $10.59(6.42,16.09)$ & $36.68(23.89,52.65)$ & $79.94(52.3 \mathrm{I}, \mathrm{I}$ I 3.86$)$ \\
\hline & 2019 & $0.13(0.04,0.29)$ & $1.00(0.46,1.85)$ & $9.93(5.66,15.73)$ & $34.04(21.11,50.46)$ & $74.93(46.95,109.61)$ \\
\hline & 2020 & $0.12(0.04,0.30)$ & $0.95(0.40,1.85)$ & $9.34(4.96,15.48)$ & $31.68(18.59,48.65)$ & $69.97(41.78,105.39)$ \\
\hline & EAPC & $-5.33(-5.53,-5.13)$ & $-5.95(-6.11,-5.79)$ & $-6.69(-6.93,-6.45)$ & $-7.13(-7.25,-7.01)$ & $-5.35(-5.77,-4.92)$ \\
\hline \multicolumn{7}{|c|}{ Female } \\
\hline & 2013 & $0.12(0.06,0.21)$ & $0.50(0.32,0.75)$ & $3.11(2.24,4.21)$ & I3.83 (I0.37, |8.07) & $48.45(36.38,63.02)$ \\
\hline & 2014 & $0.11(0.05,0.22)$ & $0.48(0.29,0.75)$ & $3.01(2.11,4.16)$ & I3.34 (9.82, I7.65) & $46.30(34.25,60.93)$ \\
\hline & 2015 & $0.11(0.05,0.22)$ & $0.47(0.27,0.76)$ & $2.91(1.97,4.13)$ & $12.86(9.25, \mid 7.32)$ & $44.36(32.17,59.24)$ \\
\hline & 2016 & $0.11(0.04,0.23)$ & $0.45(0.25,0.77)$ & $2.82(1.83,4.12)$ & $12.42(8.67,17.08)$ & $42.6 I(30.14,57.91)$ \\
\hline & 2017 & $0.10(0.04,0.23)$ & $0.44(0.23,0.78)$ & $2.73(1.69,4.14)$ & $12.00(8.08,16.93)$ & $41.03(28.16,56.93)$ \\
\hline & 2018 & $0.10(0.03,0.24)$ & $0.43(0.21,0.80)$ & $2.65(1.55,4.19)$ & II.60 (7.50, I6.87) & $39.59(26.23,56.26)$ \\
\hline & 2019 & $0.10(0.03,0.25)$ & $0.42(0.19,0.82)$ & $2.57(1.42,4.25)$ & II.24 (6.93, I6.89) & $38.24(24.34,55.84)$ \\
\hline & 2020 & $0.10(0.03,0.26)$ & $0.41(0.17,0.85)$ & $2.50(1.30,4.33)$ & $10.89(6.37,16.99)$ & $36.98(22.50,55.65)$ \\
\hline & EAPC & $-2.13(-2.32,-1.95)$ & $-2.7 \mathrm{I}(-2.85,-2.57)$ & $-3.09(-3.19,-2.98)$ & $-3.36(-3.45,-3.27)$ & $-3.76(-3.96,-3.57)$ \\
\hline
\end{tabular}

Abbreviation: EAPC, estimated annual percentage change. 
Table S3 The projection of liver cancer mortality in Shanghai from 2013 to 2020 based on the registry data, 1973-20I2

\begin{tabular}{|c|c|c|c|c|c|c|}
\hline \multirow[t]{2}{*}{ Sex } & \multirow[t]{2}{*}{ Period } & \multicolumn{5}{|c|}{ Age-specific incidence per $10^{5}(95 \% \mathrm{Cl})$} \\
\hline & & $0-19$ & $20-34$ & $35-49$ & $50-64$ & $65+$ \\
\hline \multicolumn{7}{|c|}{ Male } \\
\hline & 2013 & $0.12(0.06,0.21)$ & $1.05(0.67,1.52)$ & II.48 (8.3I, I5.40) & $43.00(31.97,56.49)$ & $96.62(7 \mid .75,127.33)$ \\
\hline & 2014 & $0.11(0.05,0.20)$ & $0.98(0.61,1.47)$ & $10.68(7.55,14.57)$ & $40.35(29.66,53.49)$ & $92.76(68.16,123.29)$ \\
\hline & 2015 & $0.11(0.05,0.20)$ & $0.92(0.54,1.43)$ & $9.95(6.84,13.87)$ & $37.69(27.29,50.61)$ & $88.74(64.31,119.22)$ \\
\hline & 2016 & $0.10(0.04,0.20)$ & $0.87(0.48,1.39)$ & $9.28(6.17,13.28)$ & $35.11(24.91,47.92)$ & $84.59(60.26,115.18)$ \\
\hline & 2017 & $0.10(0.04,0.20)$ & $0.8 \mathrm{I}(0.43, \mathrm{I} .36)$ & $8.68(5.53,12.80)$ & $32.65(22.57,45.49)$ & $80.30(56.03,111.11)$ \\
\hline & 2018 & $0.09(0.03,0.20)$ & $0.77(0.37,1.34)$ & $8.14(4.94,12.40)$ & $30.37(20.35,43.35)$ & $75.85(51.64,106.92)$ \\
\hline & 2019 & $0.09(0.03,0.20)$ & $0.72(0.33,1.33)$ & $7.64(4.40,12.09)$ & $28.29(|8.27,4| .53)$ & $71.28(47.18,102.65)$ \\
\hline & 2020 & $0.08(0.02,0.20)$ & $0.68(0.29,1.32)$ & $7.18(3.89,11.84)$ & $26.40(16.34,39.97)$ & $66.71(42.76,98.44)$ \\
\hline & EAPC & $-5.35(-5.52,-5.18)$ & $-5.92(-6.05,-5.79)$ & $-6.48(-6.66,-6.31)$ & $-6.79(-6.90,-6.68)$ & $-5.14(-5.55,-4.73)$ \\
\hline \multicolumn{7}{|c|}{ Female } \\
\hline & 2013 & $0.06(0.02,0.12)$ & $0.29(0.17,0.49)$ & $1.94(1.28,2.80)$ & $10.14(7.11,14.01)$ & $42.59(29.99,58.49)$ \\
\hline & 2014 & $0.06(0.02,0.13)$ & $0.29(0.15,0.49)$ & I.87 (1.20, 2.77) & $9.77(6.74,13.68)$ & $40.36(28.07,56.06)$ \\
\hline & 2015 & $0.06(0.02,0.13)$ & $0.28(0.14,0.50)$ & $1.80(1.12,2.76)$ & $9.42(6.36,13.43)$ & $38.39(26.28,54.08)$ \\
\hline & 2016 & $0.05(0.02,0.13)$ & $0.27(0.13,0.5 \mathrm{I})$ & $1.74(1.03,2.76)$ & $9.09(5.97,13.25)$ & $36.69(24.64,52.57)$ \\
\hline & 2017 & $0.05(0.02,0.14)$ & $0.26(0.11,0.53)$ & $1.69(0.95,2.79)$ & $8.77(5.57,13.14)$ & $35.23(23.10,51.50)$ \\
\hline & 2018 & $0.05(0.01,0.15)$ & $0.26(0.10,0.54)$ & $1.63(0.87,2.83)$ & $8.47(5.17,13.11)$ & $33.95(21.63,50.81)$ \\
\hline & 2019 & $0.05(0.01,0.15)$ & $0.25(0.09,0.57)$ & $1.59(0.79,2.89)$ & $8.19(4.78,13.14)$ & $32.78(20.20,50.44)$ \\
\hline & 2020 & $0.05(0.01,0.16)$ & $0.24(0.08,0.59)$ & $1.54(0.7 \mathrm{I}, 2.97)$ & $7.92(4.39,13.25)$ & $31.69(18.79,50.31)$ \\
\hline & EAPC & $-1.68(-1.97,-1.39)$ & $-2.64(-2.83,-2.45)$ & $-3.21(-3.33,-3.08)$ & $-3.47(-3.53,-3.4 I)$ & $-4.10(-4.44,-3.75)$ \\
\hline
\end{tabular}

Abbreviation: EAPC, estimated annual percentage change.

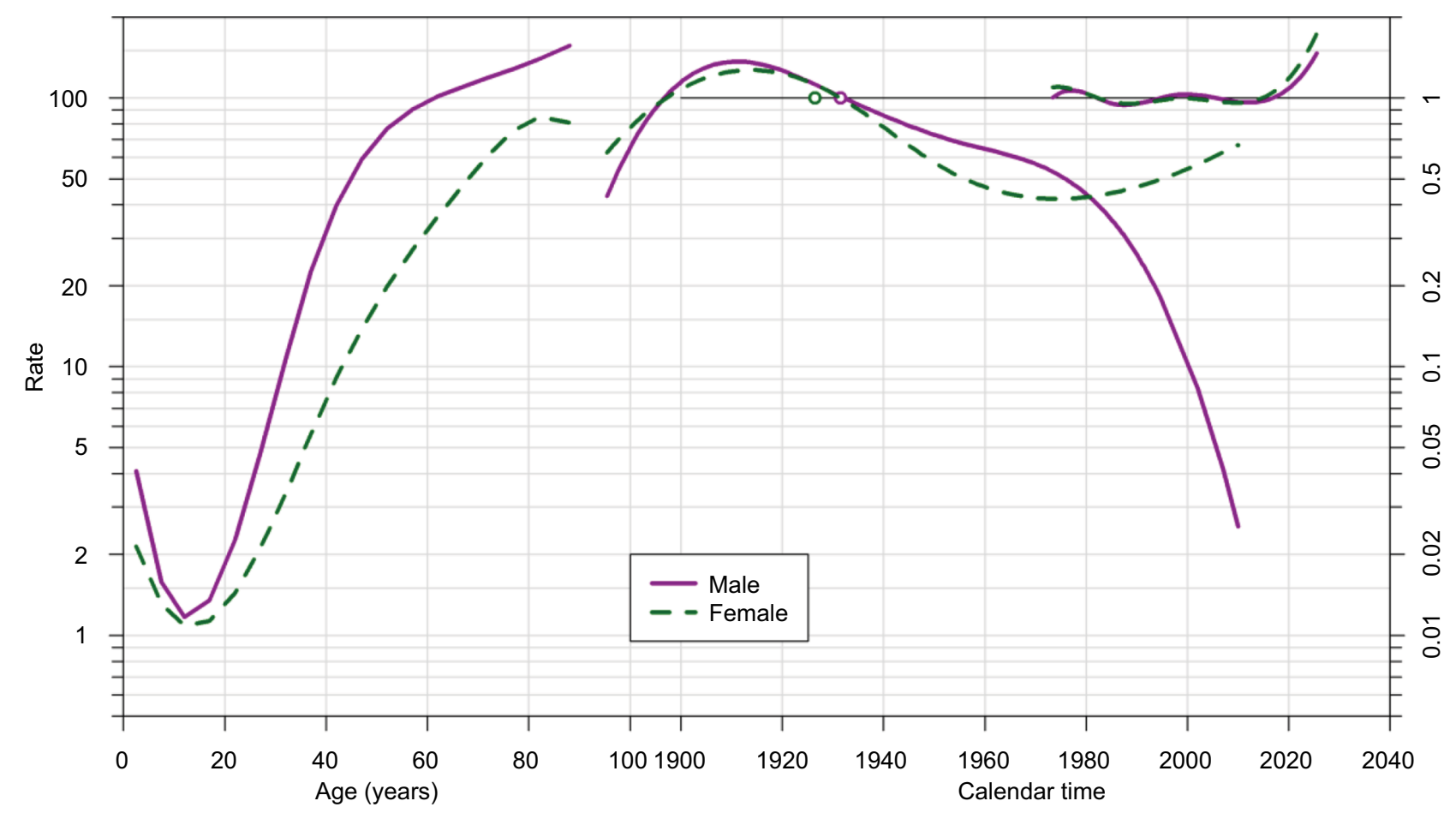

Figure SI Estimated effects of liver cancer incidence from the age-period-cohort model in males and females from 1973 to 2012 in Shanghai, China.

Notes: The left curve shows the fitted age-specific rates for $10^{5}$ person-years at risk during the reference cohort (1931.5 in male and 1926.5 in female), the middle curve displays the rate ratios of cohorts relative to the reference cohort (1931.5 in male and 1926.5 in female), and the right curve shows the rate ratios of period conditional on the estimated age and cohort effects relative to the reference period (2005). The open circle in the cohort-effect curve represents the reference birth cohort. 


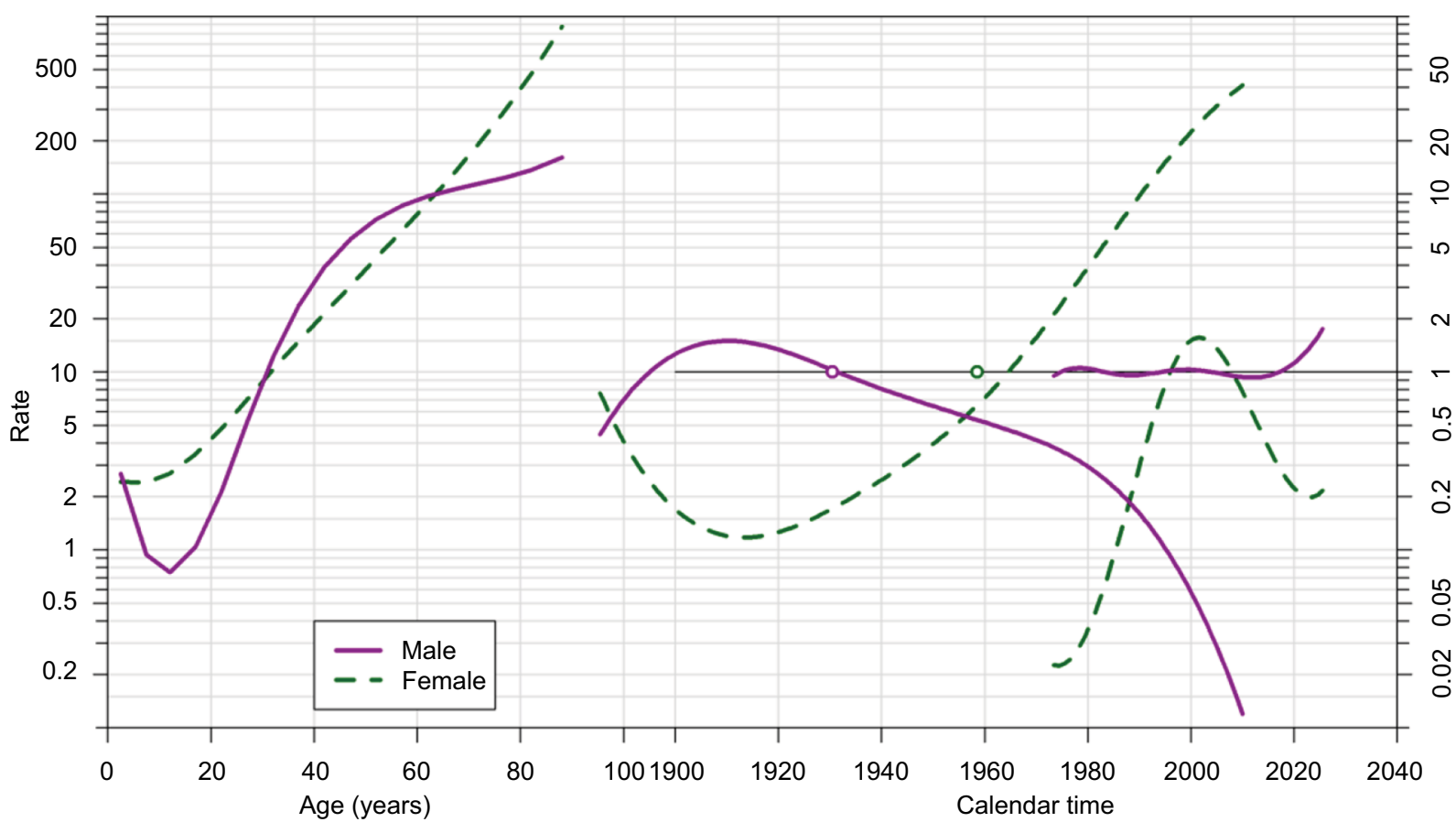

Figure S2 Estimated effects of liver cancer mortality from the age-period-cohort model in males and females from 1973 to 2012 in Shanghai, China.

Notes: The left curve shows the fitted age-specific rates for $10^{5}$ person-years at risk during the reference cohort (1930.5 in male and 1958.5 in female), the middle curve displays the rate ratios of cohorts relative to the reference cohort (1930.5 in male and 1958.5 in female), and the right curve shows the rate ratios of period conditional on the estimated age and cohort effects relative to the reference period (2005). The open circle in cohort-effect curve represents the reference birth cohort.

\section{Publish your work in this journal}

Clinical Epidemiology is an international, peer-reviewed, open access, online journal focusing on disease and drug epidemiology, identification of risk factors and screening procedures to develop optimal preventative initiatives and programs. Specific topics include: diagnosis, prognosis, treatment, screening, prevention, risk factor modification,

Submit your manuscript here: https://www.dovepress.com/clinical-epidemiology-journa systematic reviews, risk and safety of medical interventions, epidemiology and biostatistical methods, and evaluation of guidelines, translational medicine, health policies and economic evaluations. The manuscript management system is completely online and includes a very quick and fair peer-review system, which is all easy to use. 